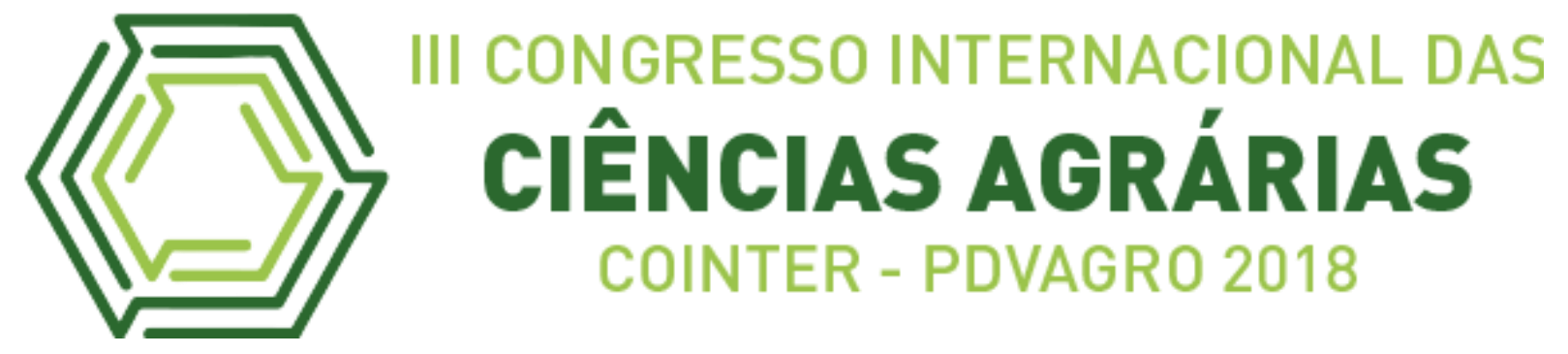

\title{
ACOMPANHAMENTO DAS ATIVIDADES TÉCNICAS DA EXTENSÃO RURAL FOCADA EM AGRICULTURA FAMILIAR NO INSTITUTO AGRONÔMICO DE PERNAMBUCO (IPA) EM LAJEDO-PE
}

\section{FOLLOW-UP OF THE TECHNICAL ACTIVITIES OF THE RURAL EXTENSION FOCUSED ON FAMILY FARMING AT THE PERNAMBUCO AGRICULTURAL INSTITUTE (IPA) IN LAJEDO-PE}

\author{
Apresentação: Relato de Experiência \\ Gabriela Fabrizia Diniz Leite ${ }^{1}$; Júlia Prates de Aguiar $^{2}$;José Ramos de Queiroz ${ }^{3}$
}

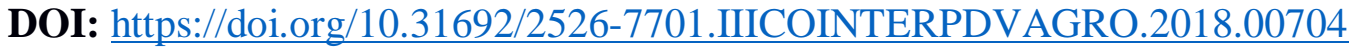

\section{Introdução}

O estágio supervisionado do curso Técnico em Agropecuária foi realizado no Instituto Agronômico de Pernambuco (IPA), situado no município de Lajedo-PE.

O presente relatório descreve a experiência obtida no acompanhamento da realização de atividades técnicas em conjunto com práticas tecnológicas e atividades de extensão rural voltadas ao atendimento das necessidades dos Agricultores, disponibilizando seus direitos garantidos por leis e projetos, como: Garantia Safra, CAR, Programas de InfraestruturaHídrica, Programa de Assistência e Extensão Rural- ATER (Crédito Rural, DAP). Cursos, seminários, oficinas, excursões, produção artesanal, contratação de carro-pipa, distribuição de semente, terra pronta (aração), Brasil sem miséria, reconstrução de barragens, programa Mãe Coruja e cadeia produtiva. Assim como, o auxílio aos Agricultores dentro da assistência técnica do extensionista rural.

Sendo assim, todas as práticas com o objetivo principal de melhorar a renda e a qualidade de vida das famílias rurais, por meio do aperfeiçoamento dos sistemas de produção, de mecanismos de acesso a recursos, serviços e renda de forma sustentável.

\section{Relato de Experiência}

Nas atividades de estágio realizadas no Instituto Agronômico de Pernambuco (IPA) estão relacionadas as ações com detalhes de execução voltadas à Agricultura Familiar, sempre

\footnotetext{
${ }^{1}$ Bacharelado em Agronomia, IFPE- Campus Vitória de Santo Antão, gabrielafabrizia99@hotmail.com

2 Bacharelado em Agronomia, IFPE- Campus Vitória de Santo Antão, juliaaguiar1036@gmail.com

${ }^{3}$ Doutor, Prof. do IFPE- Campus Belo Jardim, jramosq2003@yahoo.com.br
} 
focando naqueles que tinham menor renda e maior necessidade na sua produção, seja por falta de renda ou maquinários. Em sua maioria, as atividades consistiam em elaboração de declaração, projeto, cadastramento e acompanhamento pessoal voltado aos agricultores e agricultoras. Ou seja, atividades que permitiam maior acessibilidade tecnológica e até mesmo realizadas no próprio local de trabalho dos produtores, no campo, acompanhando mais de perto a produção.

BITTENCOURT e BIANCHINI (1996), em um estudo feito nas principais regiões do Brasil adotam a seguinte definição "Agricultor familiar é todo aquele (a) agricultor (a) que tem na agricultura sua principal fonte de renda $(+80 \%)$ e que a base da força de trabalho utilizada no estabelecimento seja desenvolvida por membros da família. É permitido o emprego de terceiros temporariamente, quando a atividade agrícola assim necessitar.

CARMO, R.B.A (2012) Uma pesquisa realizada pelo Censo agropecuário do IBGE, mostrou a importância da extensão rural no Brasil. E revelou um ponto que merece se destacado: Agricultores familiares que não recebem assistência técnica e extensão rural tem média de $\mathrm{R} \$ 700,00$; e os que recebem com frequência tem renda de $\mathrm{R} \$ 2.139,00$. O serviço de assistência Técnica e Extensão Rural, ao longo dos anos, têm contribuído significativamente para o desenvolvimento da agricultura familiar.

O objetivo principal da extensão rural dentro do Instituto Agronômico de Pernambuco (IPA) é a implantação da assistência técnica prioritariamente aos agricultores de base familiar. Gerando assim tecnologias para produtos e sistemas agropecuários, por exemplo, o Cadastro Ambiental Rural (CAR), que consiste em medições da propriedade com auxílio do GPS, realizando o registro público eletrônico das propriedades rurais em âmbito nacional. Do mesmo modo, a distribuição de tratores e maquinários para Aração no Programa "Terra Pronta";

Promovendo o acesso as políticas públicas: Programa Nacional de Fortalecimento da Agricultura Familiar (PRONAF) que consiste em financiar projetos individuais ou coletivos, gerando assim renda para os agricultores familiares e assentados da reforma agrária, geralmente procuravam o projeto para custear suas safras, investimentos em máquinas e na infraestrutura da sua propriedade; Cadeias produtivas, isto é, o arranjo de ações de organizações fornecedoras, produtoras e consumidoras para criação de valor na produção de um produto ou serviço, além de buscar competitividade no mercado ao produzir de forma mais barata ou melhor que a concorrência. Voltadas á produção de Mandioca, feijão e no 
reaproveitamento da manipueira como alimento rico em proteínas para alimentação do gado leiteiro;

Distribuição de sementes que foram entregues aos associados das comunidades distribuídas pelo IPA, onde os agricultores recebem cerca de $10 \mathrm{~kg}$ de cada semente para o plantio; e Palestras educativas cujo tema foi: "Protegendo o Meio Ambiente Para uma Melhor Qualidade de Vida", com a finalidade de discutir as maneiras corretas de descarte de lixo e da utilização dos Agrotóxicos na agricultura, onde foi esclarecida todas dúvidas dos agricultores ali presentes sobre a utilização do EPI (Equipamento de Proteção Individual), o qual a maioria não tinha conhecimento.

Foram desenvolvidas atividades de infraestrutura hídrica para o meio rural, por meio da construção, manutenção de recuperação de barragens e poços, assim como, a realização de visitas técnicas onde foram feitos levantamento de campo para a elaboração de projetos produtivos (aquisição de matrizes bovinas, reformas de cercas e construção de açudes.)

Por fim, atividades de Piscicultura também foram desenvolvidas, seguida da recomendação de correção e adubação de tanques de piscicultura onde a mortalidade de peixes ocorria por falta de oxigênio. Recomendou-se aplicação de calcário de 200 a 300 $\mathrm{kg} / 1.000 \mathrm{~m}^{2}$ de área de tanque, com o objetivo de diminuir a acidez da água, proporcionando a produção de fitoplanctons que chegam a fornecer $80 \%$ do oxigênio, demandado pelos peixes e demais organismos.

A adubação visa corrigir as deficiências de fósforo e nitrogênio que são os elementos mais deficientes nas águas, influenciando também na produção de fitoplanctons, recomendaram-se 10-15 kg/ha/ mês de sulfato de amônia.

\section{Considerações}

Constatou-se uma visão bastante ampla sobre a importância da assistência e extensão rural dentro da Agricultura familiar e o quanto melhora a qualidade de vida do agricultor e sua família, tornando-se uma atividade essencial.

Verificou-se durante o estágio muito sobre a vida do homem no campo, suas principais dificuldades, trabalho árduo na produção, cultivo da terra ou na criação de animais.

Dessa forma, cria-se uma experiência maior sobre o trabalho que estará por vim quando vai se trabalhar com extensão rural dentro das Ciências Agrárias.

\section{Referências}


BITTENCOURT, G. A.; BIANCHINI, V. Agricultura familiar na região sul do Brasil, Consultoria UTF/036-FAO/INCRA, 1996.

CARMO, R.B.A. A Questão Agrária e o Perfil da Agricultura Brasileira 1999 Disponível em http://www.cria.org.br/gip/gipaf/itens/pub/sober. 